\title{
Development of an integrated CRISPRi targeting $\Delta$ Np63 for treatment of squamous cell carcinoma
}

\author{
Masakazu Yoshida ${ }^{1}$, Etsuko Yokota ${ }^{1}$, Tetsushi Sakuma ${ }^{3}$, Tomoki Yamatsuji ${ }^{1}$, Nagio \\ Takigawa $^{2}$, Toshikazu Ushijima ${ }^{4}$, Takashi Yamamoto ${ }^{3}$, Takuya Fukazawa ${ }^{1}$ and \\ Yoshio Naomoto ${ }^{1}$ \\ ${ }^{1}$ Department of General Surgery, Kawasaki Medical School, Okayama, 700-8505 Japan \\ ${ }^{2}$ Department of General Internal Medicine 4, Kawasaki Medical School, Okayama, 700-8505 Japan \\ ${ }^{3}$ Department of Mathematical and Life Sciences, Graduate School of Science, Hiroshima University, Hiroshima, $739-8526$ Japan \\ ${ }^{4}$ Division of Epigenomics, National Cancer Center Research Institute, Tsukiji, Chuo-ku, Tokyo, 104-0045 Japan \\ Correspondence to: Takuya Fukazawa, email: fukazawat@aol.com \\ Keywords: CRISPRi; $\triangle$ Np63; squamous cell carcinoma; molecular targeted therapy
}

Received: December 18, $2017 \quad$ Accepted: May 23, $2018 \quad$ Published: June 26, 2018

Copyright: Yoshida et al. This is an open-access article distributed under the terms of the Creative Commons Attribution License 3.0 (CC BY 3.0), which permits unrestricted use, distribution, and reproduction in any medium, provided the original author and source are credited.

\section{ABSTRACT}

TP63 encodes TAp63, which is functionally similar to the tumor suppressor $T P 53$, and $\triangle N$ p63, which lacks the transcription-activating domain of TAp63 and appears potently oncogenic in squamous cell carcinomas (SCCs). In this study, we developed an integrated CRISPR interference (CRISPRi) system to selectively suppress $\triangle N$ N63 (CRISPRi 1 Np63). We engineered this CRISPRi using tandemized guide RNA expression cassettes that targeted the 50 to 100 bp downstream of the transcription start site of $\Delta \mathrm{Np} 63$ in combination with inactivated Cas9 linked to the transcription repression module Krüppel-associated box repressor domain. The plasmid vector harboring CRISPRi $\Delta N p 63$ repressed $\triangle N p 63$ transcription in lung and esophageal SCC cells. Likewise, Ad-CRISPRi $\triangle N$ p63, an all-in-one adenoviral vector containing the tandemized gRNAs and dCas9/KRAB expression cassette suppressed $\Delta$ Np63 expression in SCC cells. Ad-CRISPRi $\triangle$ Np63 also effectively decreased cell proliferation and colony formation and induced apoptosis in lung and esophageal SCC cells in vitro and significantly inhibited tumor growth in a mouse lung SCC xenograft model in vivo. These results indicate that $\Delta$ Np63 suppression using CRISPRi $\Delta N p 63$ may be an effective strategy for treating lung and esophageal SCC.

\section{INTRODUCTION}

The development of gene editing methods using engineered zinc finger nucleases (ZFNs) and transcription activator-like effector nucleases (TALENs) enabled precise genetic modification through induction of targeted DNA double-strand breaks $[1,2]$. However, the difficulty of creating the ZFN or TALEN constructs was a limitation of using these chimeric nucleases to facilitate gene targeting. A more powerful tool now available is the CRISPR/ Cas9 system, a RNA-guided site-specific DNA cleavage technology based on an immune mechanism that protects bacteria from foreign DNA. The most widely used version is CRISPR/Cas9 from Streptococcus pyogenes [3], which has two important advantages over ZFNs and TALENs. First, the design and construction of a CRISPR/Cas9 system is easier than systems using ZFNs and TALENs. Second, by introducing multiple gRNAs, CRISPR/Cas9 can be used to target several genes or sequences at the same time [4]. In addition, catalytically inactive Cas9 (dCas9) fusion protein guides that use gRNAs have been developed to target selected DNA sequences to inhibit (CRISPRi) or activate (CRISPRa) transcription of target genes [5]. 
With 1.6 million deaths annually, lung cancer is the most frequent cause of cancer-related deaths worldwide, causing [6]. However, recent progress in next-generation sequencing has enabled non-small cell lung cancer (NSCLC) patients with specific genomic alterations to benefit from molecular targeted therapies. Indeed, up to $69 \%$ of patients with advanced NSCLC could have a potentially actionable molecular target [7]. Molecularly targeted drugs for EGFR mutation or ALK fusion genes have led to remarkable improvement in personal therapies, especially in pulmonary adenocarcinoma. Several driver mutation candidates have also been identified in lung squamous cell carcinoma (SCC), though effective targeted therapies have not yet been established. Similarly, the 5-year survival rate for patients with esophageal SCC remains poor $[8,9]$ due in large part to a lack of effective treatment strategies.

TP63 is a member of the TP53 tumor suppressor family and encodes multiple isoforms of p63. Its two promoters (P1 and P2) mediate generation of two classes of proteins: TAp63, which contains an N-terminal transactivation (TA) domain, and $\Delta \mathrm{Np} 63$, an $\mathrm{N}$-terminal truncated isoform lacking the TA domain of TAp63 [10]. As a result of gene amplification, $\Delta \mathrm{Np} 63 \alpha$ is the more abundantly detected isoform in human squamous cell carcinomas, including those in the lung [11, 12], and silencing $\triangle \mathrm{Np} 63$ using siRNA suppresses growth of $\Delta \mathrm{Np} 63$-expressing cancer cells [13-15]. Conversely, overexpression of $\Delta \mathrm{Np} 63$ in normal keratinocytes and fibroblasts increased colony growth in soft agar and xenograft tumor formation in nude mice $[13,16]$. Thus, $\triangle \mathrm{Np63}$ appears to be oncogenic.

To make the most of CRISPR/Cas9, we previously established a system for construction of all-in-one expression vectors containing multiple gRNA expression cassettes and a Cas9 nuclease expression cassette and demonstrated efficient targeting for multiplex genome editing [17]. In the present study, we developed a vector containing expression cassettes with multiple gRNAs targeting $\triangle \mathrm{Np} 63$ with dCas9 fused to the KRAB (dCas9/ $\mathrm{KRAB}$ ) expression cassette $[18,19]$. We then investigated whether this integrated CRISPRi system targeting $\triangle \mathrm{Np} 63$ would exert an antitumor effect in lung and esophageal $\mathrm{SCC}$ in vitro and in vivo.

\section{RESULTS}

\section{Detection of $\Delta \mathrm{Np} 63$ expression in lung and esophageal cancer cells and normal cells}

We initially performed immunoblot assays to assess $\Delta \mathrm{Np} 63$ expression in lung and esophageal cancer cells and normal cells. As shown in Figure 1A, $\Delta$ Np63 expression was detected in EBC2 lung SCC cells and in TE8 and KYSE70 esophageal SCC cells, as well as in HBEPCs and $\mathrm{HaCaT}$ cells. By contrast, no expression was detected in any of the pulmonary adenocarcinoma cell lines test (H441, H460, H358, A549) or in NHLFs, HPMECs, HUVECs or HFF1s. TAp63 expression was detected in EBC2, H441 and H358 cells. But whereas only three of the nine human SCC cell lines tested expressed $\triangle \mathrm{Np} 63$ (EBC2, TE8 and KYSE70) [20, 21], $\Delta$ Np63 expression was detected in more than $92.5 \%$ of human lung and esophageal SCC specimens (Figure 1B). In addition, $\triangle \mathrm{Np} 63$ expression was detected in $30 \%$ of pulmonary adenocarcinomas. These results suggest $\triangle \mathrm{Np} 63$ is commonly expressed in human lung and esophageal SCC and that molecular targeting of $\Delta \mathrm{Np} 63$ may be a useful approach to treating SCC.

\section{The integrated CRISPRi system suppressed $\Delta$ Np63 transcriptional activity in lung and esophageal SCC cells}

To suppress $\triangle \mathrm{Np} 63$ expression in lung and esophageal SCC, we constructed all-in-one expression vectors containing single or double gRNA expression cassettes complementary to target sequences in the $\triangle \mathrm{Np} 63$ promoter combined with $\mathrm{dCas} 9 / \mathrm{KRAB}$ expression cassettes (pCRISPRi $\triangle N p 63 \mathrm{~A}$ and pCRISPRi $\triangle N p 63 \mathrm{~A} / \mathrm{B}$, respectively) (Figure $2 \mathrm{~A}$ and $2 \mathrm{~B}$ ). To test the efficacy of these vectors, we measured $\Delta \mathrm{Np} 63$ transcriptional activity in lung and esophageal SCC cells with and without expression of gRNAs complementary to the target sequences in the $\triangle \mathrm{Np} 63$ promoter along with $\mathrm{dCas} 9 / \mathrm{KRAB}$ expression. In the controls, which lacked gRNA expression, the promoter regions $-2000 /+140$ and $-600 /+140$, which contain the gRNA targeted sites, exhibited significant increases in transcriptional activity in EBC2 lung SCC cells (5.03-fold and 7.30-fold, respectively), in TE8 esophageal SCC cells (24.9-fold and 17.8-fold, respectively), and in KYSE70 esophageal SCC cells (3.65-fold and 3.47-fold, respectively) $24 \mathrm{~h}$ after transfection (Figure $3 \mathrm{~A}$ and $3 \mathrm{~B}$ ). On the other hand, pCRISPRi $\triangle N p 63 \mathrm{~A}$ and pCRISPRi $\triangle N p 63 \mathrm{~A} / \mathrm{B}$ significantly decreased transcriptional activity in $\triangle \mathrm{Np} 63$ promoter region $-600 /+140$ in EBC2 cells (4.35-fold and 3.08-fold, respectively), TE8 cells (10.5-fold and 5.28-fold, respectively), and KYSE70 cells (1.94-fold and 0.95 -fold, respectively). pCRISPRi $\Delta N p 63 \mathrm{~A} / \mathrm{B}$ also significantly suppressed transcriptional activity of the $\Delta$ Np63 promoter region $-2000 /+140$ in EBC2 cells (3.70-fold), TE8 cells (8.85-fold) and KYSE70 cells (1.23-fold). These results indicate that $\mathrm{pCRISPRi} \Delta \mathrm{Np} 63 \mathrm{~A} / \mathrm{B}$ more effectively suppressed $\triangle \mathrm{Np} 63$ transcriptional activity than pCRISPRi $\triangle N p 63 \mathrm{~A}$ in these SCC cell lines (Figure 3A, 3B and Supplementary Figure 1). Likewise, pCRISPRi $\triangle N p 63 A / B$ inhibited expression of $\Delta \mathrm{Np} 63$ protein more effectively than did pCRISPRi $\Delta$ Np63A in EBC2 and TE8 cells (Supplementary Figure 2). Thus the integrated CRISPRi system targeting $\triangle \mathrm{Np} 63$ significantly suppresses $\triangle \mathrm{Np} 63$ expression in lung and esophageal SCC cells, and using double gRNAs that target different promoter 
regions in the same gene at the same time suppresses the transcriptional activity and protein expression more effectively than using a single gRNA.

\section{Ad-CRISPRi $\Delta$ Np63 suppresses $\Delta$ Np63 expression in SCC cells and immortalized keratinocytes}

We next evaluated whether $\Delta \mathrm{Np} 63$ expression could be suppressed in SCC cells and keratinocytes using an all-in-one adenoviral vector containing double gRNA expression cassettes and a dCas9/KRAB expression cassette to target $\Delta$ Np63 (Ad-CRISPRi $\Delta$ Np63) (Figure 4A). We found that Ad-CRISPRi $\Delta$ Np63 dose dependently increased dCas9 expression in EBC2 lung SCC cells, TE8 and KYSE70 esophageal SCC cells, and $\mathrm{HaCaT}$ immortalized keratinocytes $48 \mathrm{~h}$ after infection. Moreover, Ad-CRISPRi $\Delta$ Np63 clearly suppressed $\Delta$ Np63 expression in all tested cell lines. On the other hand, the control vector did not effectively inhibit $\triangle \mathrm{Np} 63$ expression in the cells (Figure 4B).
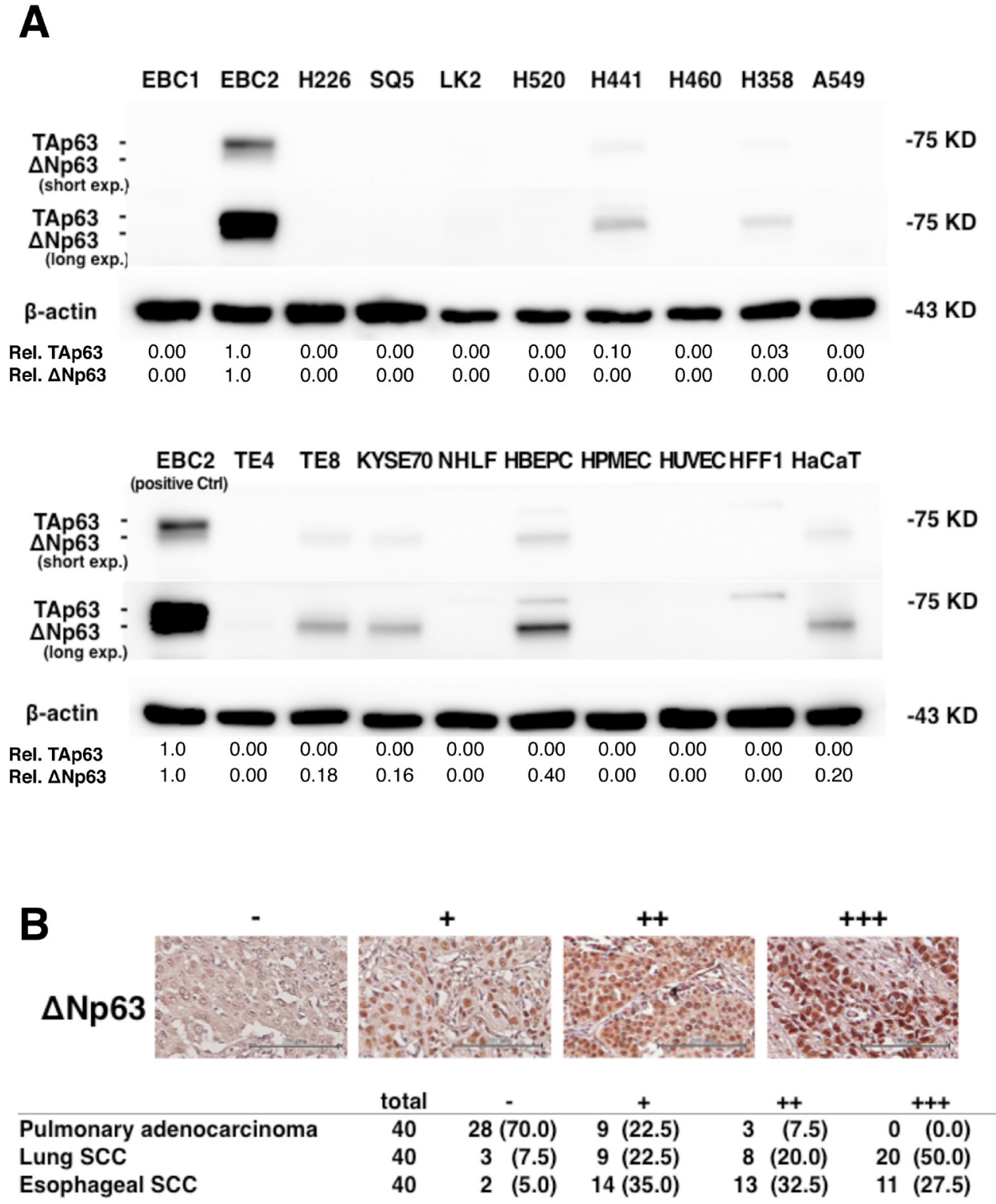

Figure 1: $\Delta$ Np63 expression in lung and esophageal SCC and pulmonary adenocarcinoma. (A) Immunoblot analysis of TAp63 and $\Delta$ Np63 expression in the indicated cells. $\beta$-actin served as a control. A non-specific band with higher molecular weight than TAp63 $(75 \mathrm{kDa})$ was seen in HBEPCs and HFF1s. Band densities normalized to the EBC2 cell band are shown below the blots. (B) Representative immunohistochemistry results. $\triangle$ Np63 staining intensity was scored as follows: none $=-$, weak $=+$, moderate $=++$, and strong $=+++$ expression. Scale bars $=200 \mu \mathrm{m}$. Shown below are the frequencies of $\Delta \mathrm{Np} 63$ expression in samples of primary pulmonary adenocarcinoma, lung SCC, and esophageal SCC. Percentages are given in parentheses. 
Ad-CRISPRi $\triangle N p 63$ suppresses colony formation and induces apoptosis in $\triangle \mathrm{Np63expressing} \mathrm{SCC}$ cells and immortalized keratinocytes

To elucidate the antitumor effect of the AdCRISPRi $\triangle \mathrm{Np} 63$ system, we assessed colony formation by in SCC cells and keratinocytes after Ad-CRISPRi $\triangle N p 63$ infection. As shown in Figure 5A and 5B, AdCRISPRi $\triangle$ Np63 significantly decreased colony formation by EBC2, TE8, KYSE70, and HaCaT cells. TUNEL assays revealed that the incidence of apoptosis was increased in EBC2 and $\mathrm{HaCaT}$ cells $48 \mathrm{~h}$ after Ad-CRISPRi $\Delta$ Np63 infection. By contrast, little or no apoptosis was seen in NHLFs and HUVECs after Ad-CRISPRi $\triangle$ Np63 infection (Figure 5C, 5D and Supplementary Figure 3). Hoechst staining also showed the presence of apoptotic cells among $\mathrm{EBC} 2$ cells after Ad-CRISPRi $\triangle \mathrm{Np} 63$ infection, but not among NHLFs (Supplementary Figure 4). These results indicate that Ad-CRISPRi $\triangle \mathrm{Np} 63$ exerts an antitumor effect against $\Delta \mathrm{Np} 63$-positive $\mathrm{SCC}$ cells and immortalized keratinocytes, but not normal fibroblasts or endothelial cells.

\section{Down-regulation of $\Delta N p 63$ suppresses lung SCC growth in a xenograft mouse model}

In addition to the cell-based experiments, we used an EBC2 lung SCC xenograft tumor model in nude mice to determine whether CRISPRi $\triangle \mathrm{Np} 63$ suppresses tumor growth in vivo. We found that tumor growth was significantly suppressed after Ad-CRISPRi $\triangle$ Np63 infection at a MOI of 300 (Figure 6) or 600 (Supplementary Figure 5). These results indicate that Ad-CRISPRi $\Delta$ Np63 exerts a marked antitumor effect against lung $\mathrm{SCC}$ in vivo.

\section{DISCUSSION}

Although use of RNAi may be the simplest approach to knocking down expression of a target gene [22], it sometimes exhibits marked off-target effects and unpredictable knockdown efficiencies [23, 24]. CRISPRi provides more consistent and robust gene knockdown in mammalian cells [25]. However, previous studies have shown that CRISPR/Cas9 can frequently cause off-target

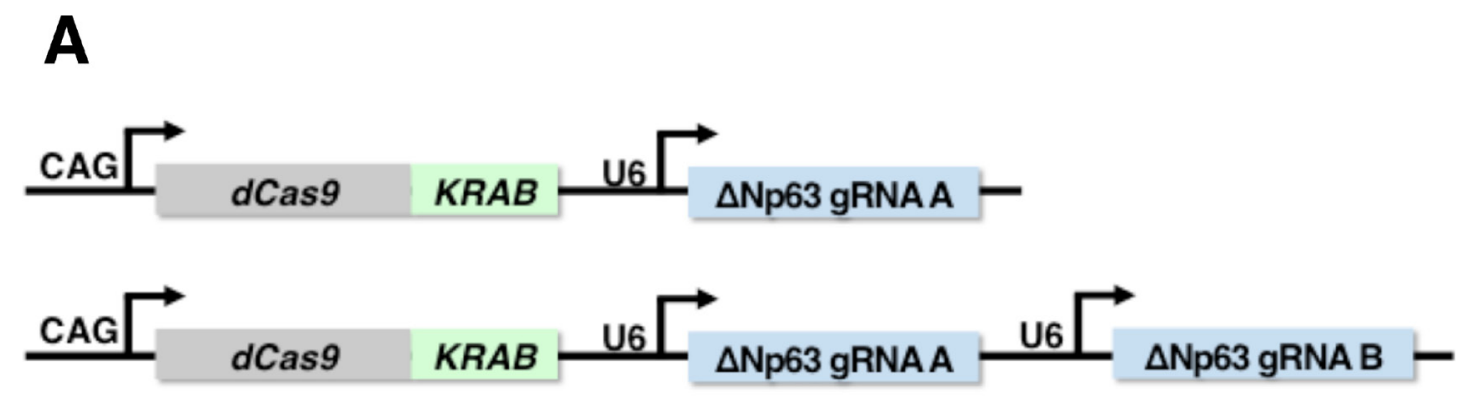

B

-150 ATTCTAACTACTTAATGAGATGGGAGAGGCCTCACTCCATTGGAGTGGAGGAGTCCAGGT

-90 GGAAGTTGATGGATTGGACAGGTAAAGAGAAGAGTCCCGCCTCCTCATGCCTATAGTTGG TATA BOX Transcription start site (TSS)

-30 GATATAT TAGGAAACCTTAAATTATGTACAGAGAGAGAAAGAGAGAGAGGGACTTGAGT

$\triangle$ Np63 CRISPR gRNA sequence $A$

$\mathbf{+ 3 0}$ TCTGTTATCTTCTTAAGTAGATTCATATTGTAAGGGTCTCGGGGTGGGGGGGTTGGCAAA

$\triangle N p 63$ CRISPR gRNA sequence B

+90 ATCCTGGAGCCAGAAGAAAGG ACAGCAGCATTGATCAATCTTACAGCTAACATGTTGTAC

Figure 2: Multiplex gene targeting using dCas9/KRAB and tandemized gRNA expression cassettes. (A) Schematic representation of an integrated CRISPRi system encoding single or double gRNAs targeting different genomic loci and a dCas $9 / \mathrm{KRAB}$ fusion protein. These dCas9/KRAB and gRNAs expression cassettes were ligated into a single construct (pCRISPRi $\triangle N p 63 \mathrm{~A}$ and pCRISPRi $\triangle$ Np63A/B, respectively). (B) Sequence of the $\triangle$ Np63 proximal promoter. Broken lines indicate the gRNA targeting sequences. A TATA box and the transcription start site (TSS) are also indicated. 
mutagenesis [26, 27], though several strategies have been developed to reduce off-target effects of CRISPRi $[28,29]$. In addition, ChIP sequencing showed that dCas9 binds to a number of off-target sites and most dCas9gRNA complexes are able to bind to non-target sites $[30,31]$. Apparently, there are numerous potential nonspecific binding sites for Cas9 and dCas9. It is noteworthy, however, that CRISPRi is strongly dependent on the genomic loci of dCas9 binding. Down-regulation of gene expression requires $\mathrm{dCas} 9 / \mathrm{KRAB}$ to be targeted to a narrow window of DNA extending from 50 to $100 \mathrm{bp}$ downstream of the transcription start site (TSS) [25]. It would therefore be expected that off-targeted binding of dCas $9 / \mathrm{KRAB}$ to sites other than that small window would not induce transcriptional repression. These results indicate that CRISPRi using dCas9/KRAB and gRNAs is much safer than a Cas9-based gene knockout system or RNAi, which both exhibit greater off-target effects.

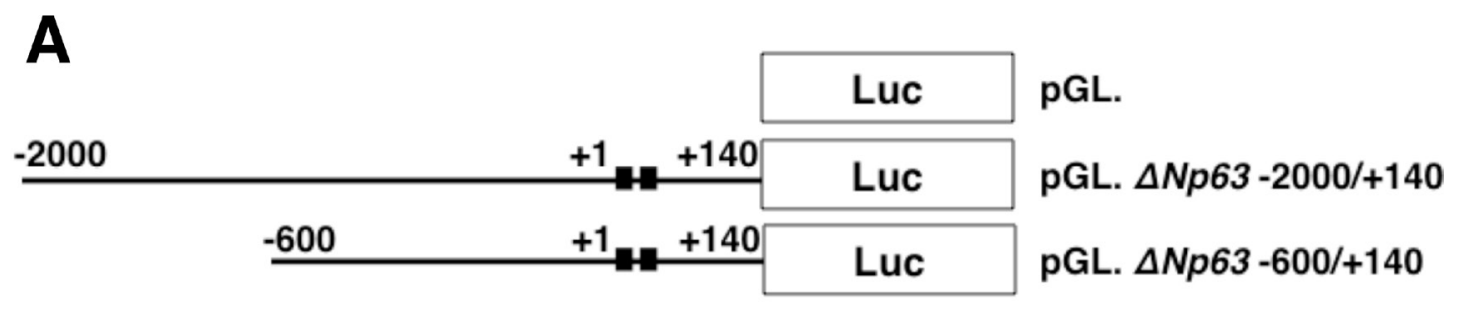

gRNA targeting site:
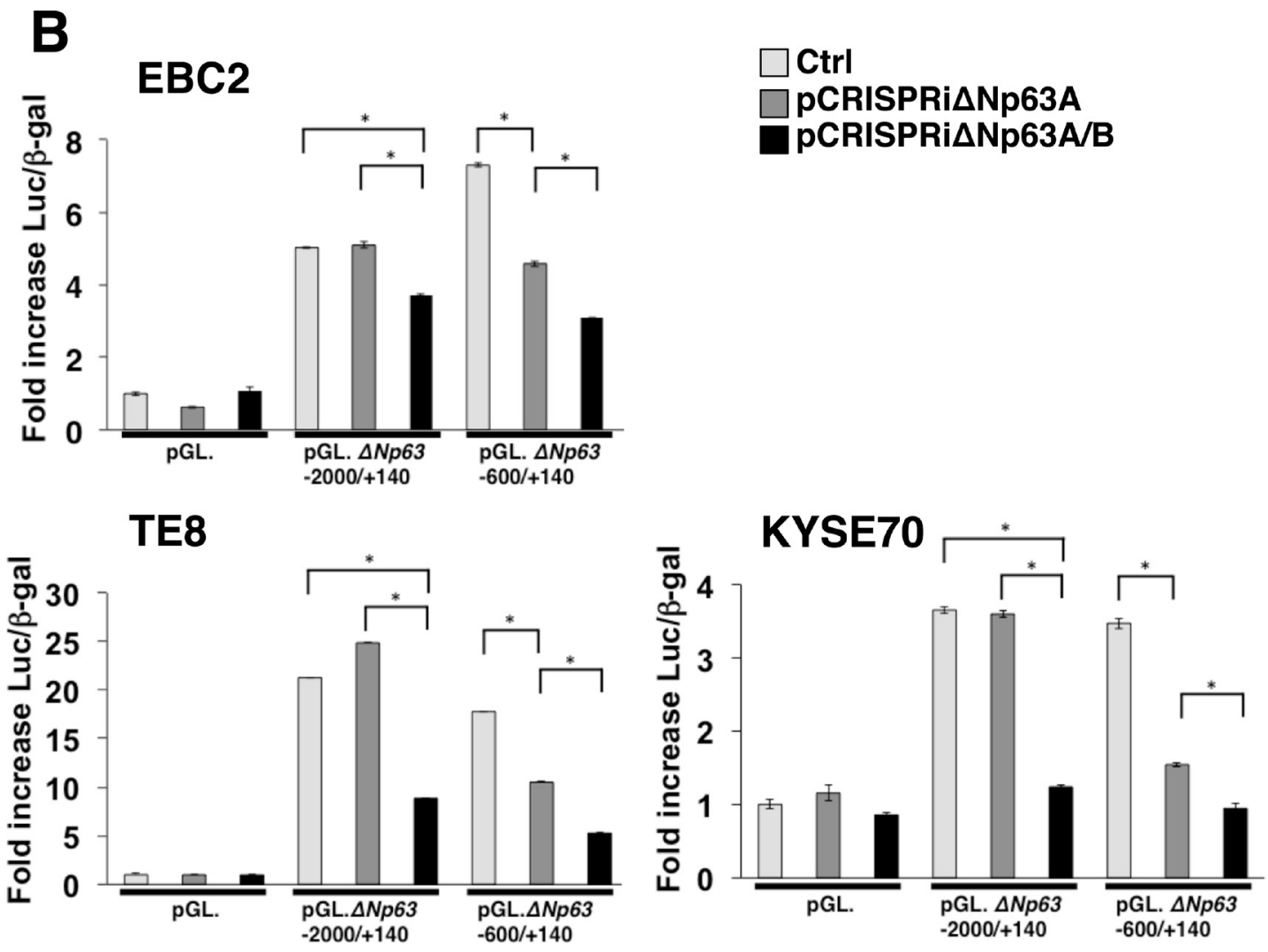

Figure 3: Repression of $\Delta \mathrm{Np} 63$ promoter activity using a CRISPRi system targeting $\Delta \mathrm{Np} 63$ in lung and esophageal SCC cells. (A) Schematic representation of $\triangle N p 63$ distal and proximal promoter reporter constructs. Luc; Luciferase. (B) Transient transfection reporter assays in EBC2 lung SCC cells and TE8 and KYSE70 esophageal SCC cells using the indicated $\triangle N p 63$ luciferase reporter constructs $(2 \mu \mathrm{g}, \mathrm{pGL})$ with $\mathrm{dCas} 9 / \mathrm{KRAB}+\mathrm{gRNA}$ expression constructs (pCRISPRi $\Delta \mathrm{Np} 63 \mathrm{~A}$ or pCRISPRi $\Delta \mathrm{Np} 63 \mathrm{~A} / \mathrm{B}, 2 \mu \mathrm{g}$ ) and pCMV. $\beta$-gal $(1 \mu \mathrm{g})$. pX330A_dCas9/KRAB-1x2 vector, not expressing gene-specific gRNA but expressing dCas9/KRAB, was used as control (Ctrl). Results are presented as fold induction of relative light units normalized to $\beta$-galactosidase activity relative to that observed with control constructs. Bars represent the mean $\pm \operatorname{SD}(n=3) .{ }^{*} p<0.01$. Each experiment was repeated at least three times, and supplementary data sets are shown in Supplementary Figure 1. 
The main practical advantage of the CRISPR/ Cas9- or CRISPR-based approach (e.g., CRISPR i/a), as compared to ZFNs or TALENs, is the ease of multiplexing [4]. The simultaneous binding of Cas9 or the dCas9/ KRAB-gRNA complex at multiple genomic loci could enable one to edit, repress or activate several genes simultaneously. In the present study, the single or double gRNA expression cassettes complementary to the target sequences in the $\Delta \mathrm{Np} 63$ promoter effectively suppressed expression of $\triangle \mathrm{Np} 63 \mathrm{mRNA}$ and protein in the presence of dCas9/KRAB. Moreover, double gRNA expression systems simultaneously targeting different promoter regions in the same gene more effectively suppress transcriptional activity than using a single gRNA.

Recently, Hussein et al. use transcriptomes derived from epidermal cells from TAp63-/- and $\Delta \mathrm{Np} 63-/-$ mice to conduct pan-cancer analysis of The Cancer Genome
Atlas (TCGA) to identify transcriptional networks regulated by TAp63 and $\Delta \mathrm{Np} 63$ [32]. They identified lymphoid enhancer-binding factor 1 (LEF1) as a major downstream target of $\Delta \mathrm{Np} 63$ that plays a crucial role in cancer development, and the activity of $\Delta \mathrm{Np} 63$ was pleiotropic in various kinds of cancer, suggesting LEF1 could be another useful target for the treatment of certain cancers, including SCC. On the other hand, TNF- $\alpha$, Ras and TGF- $\beta$ may work as upstream regulatory signals of $\triangle \mathrm{Np} 63$ that stimulate cancer progression $[33,34]$.

TP63 is also known to be a critical transcription factor in some organs [35]. On the other hand, $\Delta \mathrm{Np} 63$ is reportedly the major isoform in human lung, where it is expressed exclusively in epithelial basal cells [36]. In the present study, $\Delta \mathrm{Np} 63$ was detected not only in cancer cells and immortalized keratinocytes but also in normal basal cells from human bronchial epithelium. This

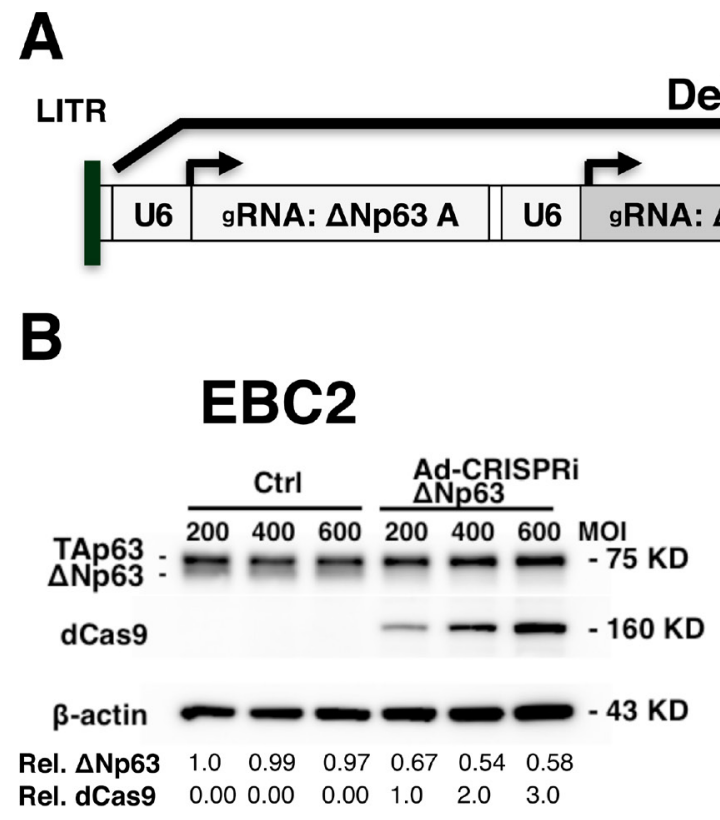

Delta E1

RITR

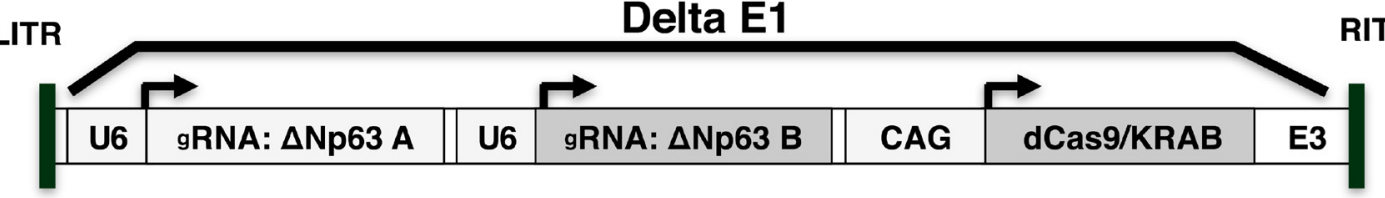

B
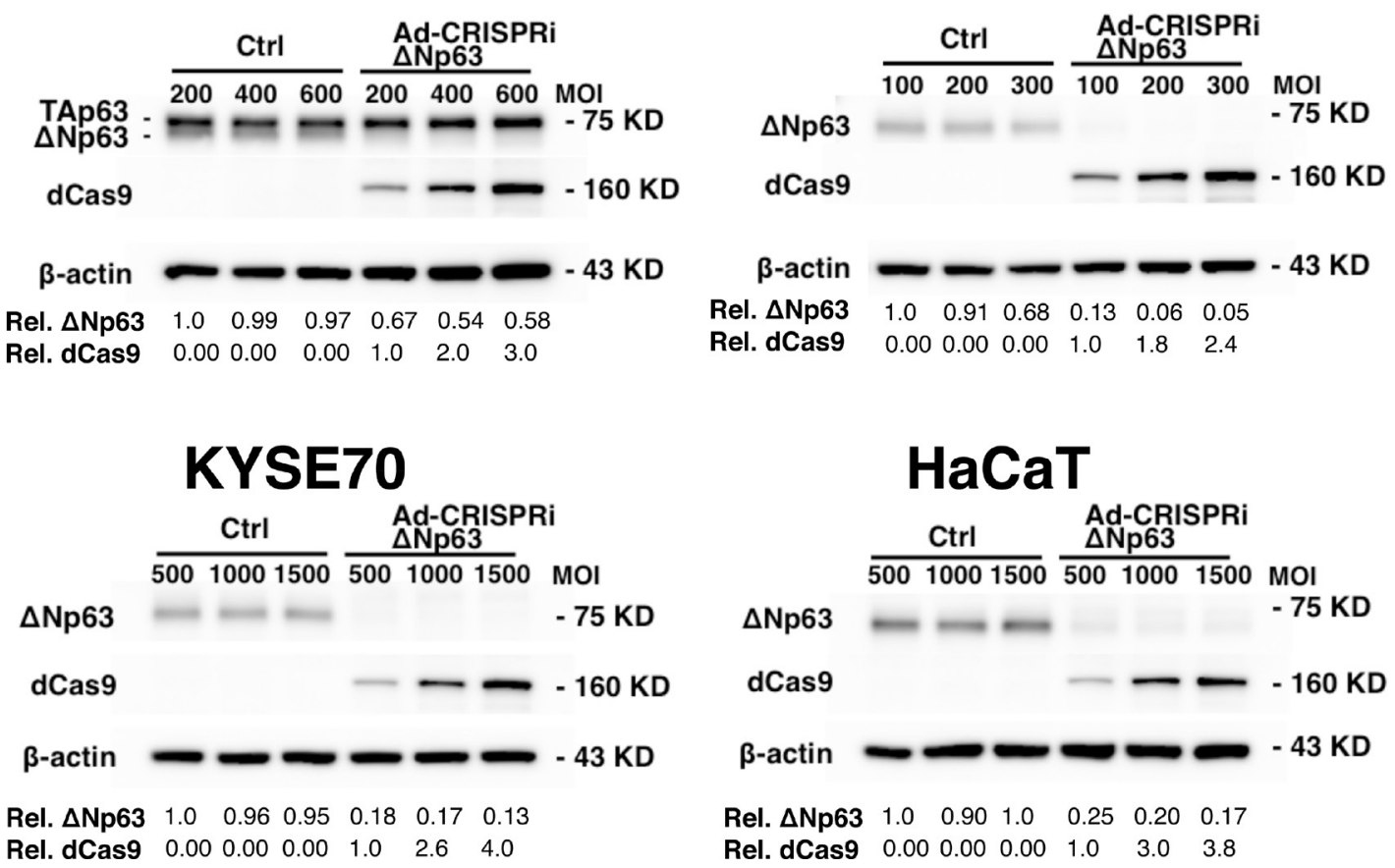

Figure 4: Ad-CRISPRi $\Delta$ Np63 suppressed $\Delta$ Np63 expression in lung and esophageal SCC cells and in immortalized keratinocytes. (A) Schematic representation of the all-in-one adenoviral vector Ad-CRISPRi $\triangle N p 63$, which encodes double gRNAs with dCas9/KRAB. (B) Immunoblot analysis showing Ad-CRISPRi $\triangle N p 63$ suppresses $\triangle$ Np63 expression in EBC2 lung SCC cells, KYSE70 and TE8 esophageal SCC cells, and HaCaT immortalized keratinocytes $48 \mathrm{~h}$ after adenoviral infection. In EBC2 cells, both TAp63 (upper band) and $\Delta \mathrm{Np} 63$ (lower band) were detected. Relative band densities are shown below the blots. For $\Delta$ Np63, band densities normalized to Adempty administered at the lowest MOI. For dCas9, band densities are normalized to Ad-CRISPRi $\Delta$ Np63 administered at the lowest MOI. 
indicates CRISPRi $\triangle N p 63$ may injure normal cells that express $\Delta$ Np63 (Figure 1A, Supplementary Figure 6). For clinical use, therefore, we plan to locally inject AdCRISPRi $\triangle N p 63$ into lung and esophageal SCC using bronchoscopy and digestive endoscopy, to minimize normal tissue and cell damage which might occur with systemic injection. Importantly, Purushothama et al. observed that when basal cells are injured, luminal secretory cells can dedifferentiate into basal cells to compensate for the loss of basal cellular function [37].

Viral vectors are the most effective means of introducing genetic material into various kinds of cells in vitro and in vivo. Adenoviral vectors are non-enveloped, non-integrating double stranded DNA vectors that enter

A

EBC2

TE8
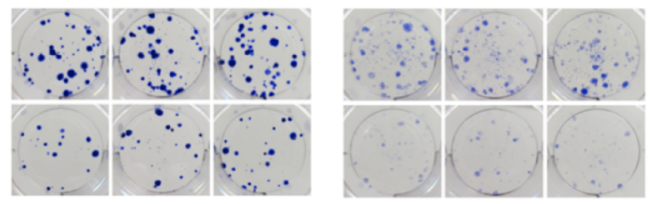

Ctrl

Ad-CRISPRi $\triangle$ Np63

B

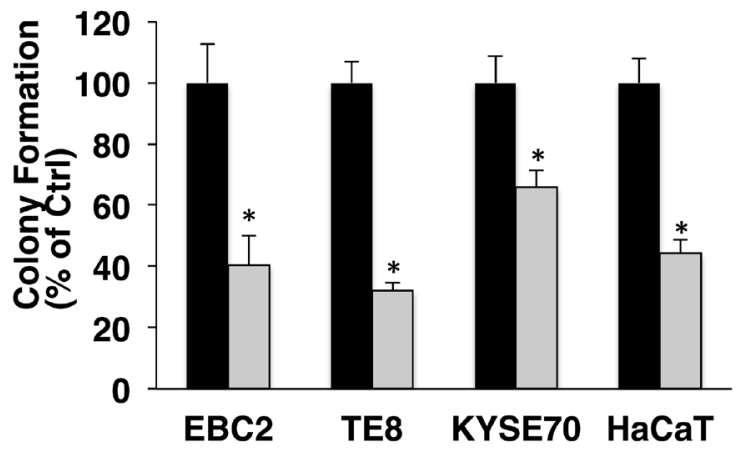

Ctrl

Ad-CRISPRi $\Delta$ Np63

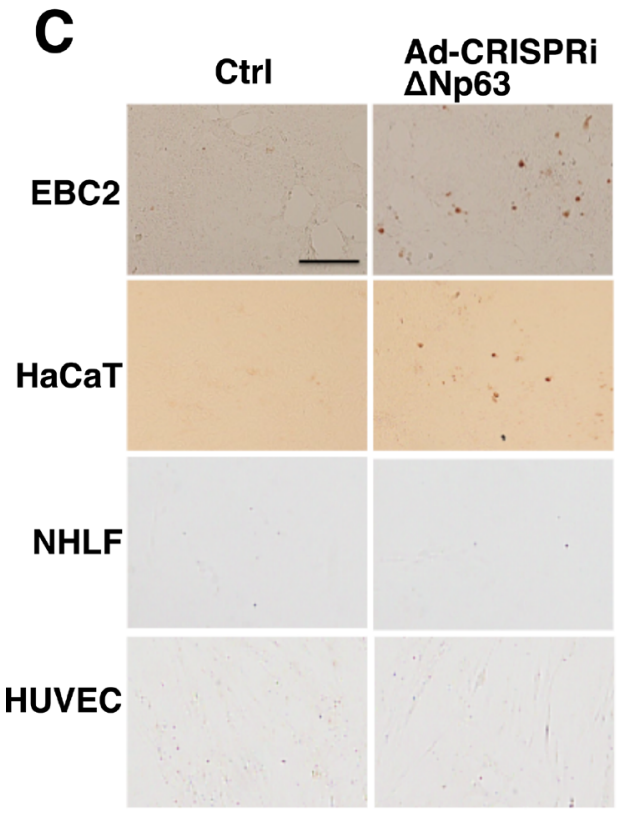

D

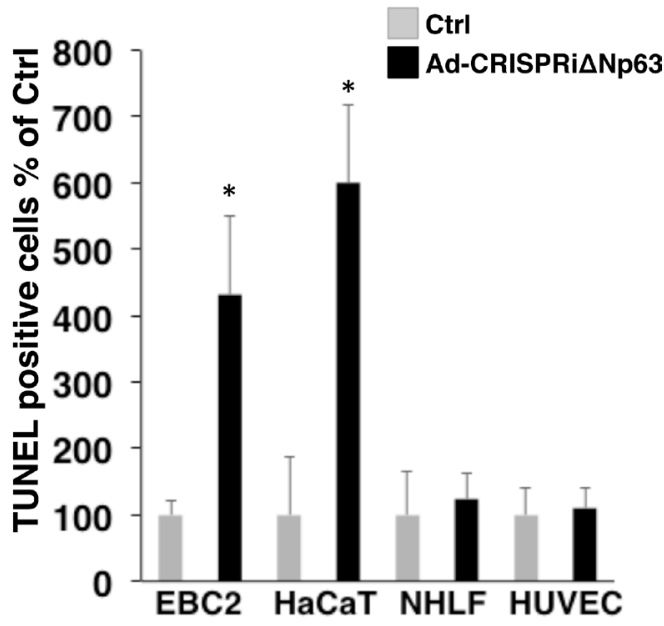

Figure 5: Ad-CRISPRi $\Delta$ Np63 significantly decreases colony formation and induces apoptosis in $\Delta N p 63$-expressing SCC cells and keratinocytes. (A) Colony formation by EBC2 lung SCC cells, TE8 and KYSE70 esophageal SCC cells, and HaCaT cells treated with Adempty (Ctrl) or Ad-CRISPRi $\triangle$ Np63. Shown are representative images of experiments performed in triplicate with EBC2 and TE8 cells. (B) Mean colony numbers derived from triplicate dishes for each treatment. Counts obtained in the control condition (Ctrl) were arbitrarily set to $100 \%$, and Ad-CRISPRi $\Delta$ Np63 is shown relative to Ctrl. Bars depict the mean \pm SD $(n=3) .{ }^{*} p<0.01$. (C) Ad-CRISPRi $\triangle$ Np63 increases the incidence of TUNEL-positive cells among EBC2 and HaCaT cells but not NHLFs or HUVECs $48 \mathrm{~h}$ after infection. Adenoviral vectors were administered at a MOI of 600 for EBC2 cells, 1500 for HaCaT cells, and 50 for NHLFs and HUVECs. Shown are representative images of experiments. Scale bar $=200 \mu \mathrm{m}$. (D) Mean TUNEL-positive cells/per field. Bars depict the mean \pm $\mathrm{SD}(n=5)$. Data are shown relative to the control group. ${ }^{*} p<0.01$. 
cells mainly via coxsackie-adenovirus receptors. These vectors can effectively deliver genes into a broad range of cell types, whether dividing and non-dividing. This is unlike single stranded RNA retroviral vectors, which require dividing cells. Both adenoviral and adenoassociated viral vectors are considered safe because they do not integrate into the host chromosome and pose no risk of genotoxicity or insertional mutagenesis [38, 39]. Importantly, adeno-associated viral vectors are classified as non-pathogenetic and can be used under the lowest biosafety standards in any laboratory. However, these vectors have a limited packaging capacity (up to $4.7 \mathrm{~kb}$ ) [40]. Adenoviral vectors have a larger cargo capacity (up to $35 \mathrm{~kb}$ ) [41], which enabled us to construct the all-in-one adenoviral vector used in this study. The advantage of allin-one vectors is that dCas9 and gRNAs are consistently delivered to, and expressed in, the same cell in a fixed ratio $[17,42]$.

In this study we used integrated adenoviral CRISPRi technology to successfully induce an anti-tumor effect in lung and esophageal SCCs. One major disadvantage of adenoviral vectors relates to their ability to induce inflammation [43, 44], which compromises their efficacy and safety in clinical trials. Recently, however, it was reported that gutless adenoviral vectors constructed by eliminating all residual viral genes stimulated less T-cell immune activity $[45,46]$. In addition to the usage of these kinds of vectors, cancer and/or tissuespecific promoter systems and tumor-selective replication competency should result in safer and more effective therapies based on adenovirally mediated CRISPRi system that are useful for effective treatment of lung and esophageal SCC [47, 48].

\section{MATERIALS AND METHODS}

\section{Cell lines and culture conditions}

H520 and H226 human lung SCC cells; H358, H441, H460 and A549 human pulmonary adenocarcinoma cells; TE4 and TE8 human esophageal SCC cells; and HFF1 human foreskin fibroblasts were obtained from the American Type Culture Collection (Manassas, VA, USA) and grown in RPMI 1640 (H226, H358, H460, TE4, TE8) or high-glucose Dulbecco's modified Eagle medium (DMEM) (H520, H441, A549, HFF1) supplemented with $10 \%$ heat-inactivated fetal bovine serum (FBS). KYSE70 human esophageal SCC cells were obtained from the Japanese Collection of Research Bioresources (Tokyo, Japan) and grown in RPMI 1640 supplemented with $10 \%$ heat-inactivated FBS. EBC1, EBC2, SQ5 and LK2 lung SCC cells were kindly provided by Dr. Katsuyuki Kiura (Department of Respiratory medicine, Okayama University Graduate School of Medicine and Dentistry, Okayama, Japan) and grown in RPMI 1640 supplemented with $10 \%$ heat-inactivated FBS. HaCaT spontaneously immortalized keratinocytes were a kind gift from Dr. Yumi Aoyama (Department of Dermatology, Kawasaki Medical School) and were grown in high glucose DMEM supplemented with 10\% heat-inactivated FBS. Human umbilical vein endothelial cells (HUVECs) were purchased from Thermo Fisher Scientific (Rockford, IL, USA) and grown in Endothelial Cells Growth Medium (Medium 200) supplemented with Low Serum Growth Supplement using a kit from Thermo Fisher Scientific. Normal human lung fibroblasts (NHLFs) were obtained from

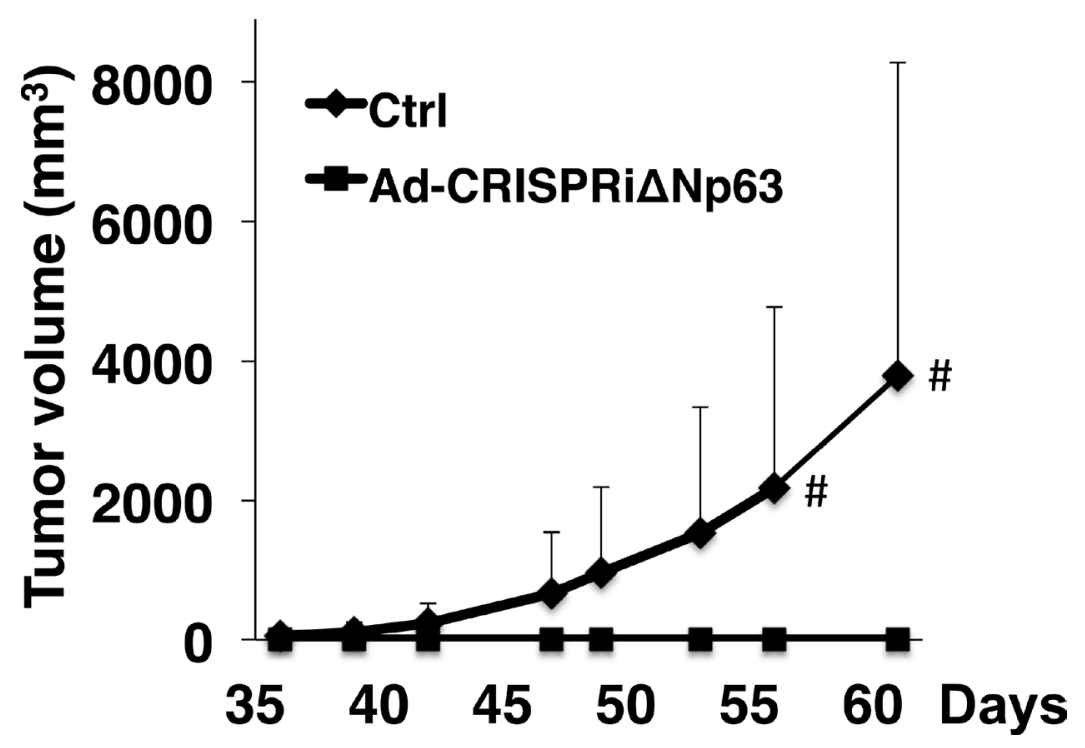

Figure 6: Ad-CRISPRi $\triangle$ Np63 significantly reduces lung SCC growth in a mouse xenograft model. Shown are volumes of tumors derived from EBC2 lung SCC cells treated with Ad-empty (Ctrl) or Ad-CRISPRi $\triangle N p 63$. Prior to the inoculations, cells were infected with adenoviral vectors at a MOI of 300. Symbols depict the mean tumor volume + SD $\left(n=10\right.$ in each group). ${ }^{\#} p<0.05$. In the control group, xenograft tumors developed in 5 of 10 mice but in none of the 10 mice in the Ad-CRISPRi $\Delta$ Np63 group ( $p=0.0389$; Fisher's exact test). 
Clonetics (San Diego, CA, USA) and grown in highglucose DMEM with $10 \%$ heat-inactivated FBS. All cell lines were cultured in $5 \% \mathrm{CO}_{2}$ at $37^{\circ} \mathrm{C}$. Cell pellets of human bronchial epithelial cells (HBEPCs) and human pulmonary microvascular endothelial cells (HPMECs) were purchased from PromoCell (Heidelberg, Germany).

\section{Construction of pCRISPRi $\Delta \mathrm{Np} 63 \mathrm{~A}$ and pCRISPRi $\triangle N$ p63A/B plasmid vectors}

The pCRISPRi $\triangle N p 63 \mathrm{~A}$ and pCRISPRi $\triangle \mathrm{Np} 63 \mathrm{~A} / \mathrm{B}$ plasmids were constructed using a Multiplex CRISPR/Cas9 Assembly System Kit (Addgene, Cambridge, MA, USA; Kit \#1000000055) and a Multiplex CRISPR dCas9/FokI-dCas9 Accessory Pack (Addgene, Kit \# 1000000062) as previously described [17, 49] with some modification. Briefly, KRAB domain was added to the pX330A_dCas9-1x2 vector contained in the Accessory Pack using PCR amplification and an In Fusion HD Cloning Kit (Takara Bio Inc., Otsu, Japan), yielding $\mathrm{pX} 330 \mathrm{~A} \mathrm{dCas} 9 / \mathrm{KRAB}-1 \times 2$. The oligonucleotides for the template of gRNAs targeting $\triangle \mathrm{Np} 63$ were then annealed and inserted into pX330A_dCas9/KRAB-1 $1 \times 2$ and into $\mathrm{pX} 330 \mathrm{~S}-2$, which was contained in the Assembly System Kit, to create pCRISPRi $\triangle$ Np63A and pCRISPRi $\Delta$ Np63B, respectively. To construct pCRISPRi $\triangle \mathrm{Np} 63 \mathrm{~A} / \mathrm{B}$, pCRISPRi $\Delta$ Np63A and pCRISPRi $\triangle$ Np63B were assembled using the Golden Gate cloning method as described previously [17]. The sequences of the oligonucleotides for the gRNA templates were as follows: $\triangle N$ p63A_s, CACCGATTCATATTGTAAGGGTCT; $\triangle$ Np63A_as,

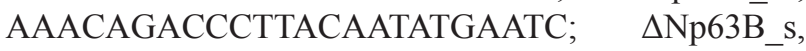
CACCGAAATCCTGGAGCCAGAAGAA; and $\triangle \mathrm{Np} 63 \overline{\mathrm{B}}$ as, AAACTTCTTCTGGCTCCAGGATTTC.

\section{Luciferase reporter construct and transient transfection reporter assay}

$\triangle \mathrm{Np63}$ promoter from human genomic DNA was obtained from Invitrogen Life Technologies (Carlsbad, CA, USA). The position of the transcription start site $(+1)$ for $\Delta \mathrm{Np} 63$ was determined using the Ensembl Human Genome browser. The luciferase reporter constructs pGL. $\Delta$ Np63 2000/+140 and pGL. $\Delta \mathrm{Np} 63-600 /+140$ were generated by subcloning the $\Delta$ Np63 promoter region $-2000 /+140$ or $-600 /+140$ amplified from genomic DNA using PCR primers $\left(5^{\prime}\right.$-ctcggeggec ${ }^{\text {HindIIII }}$ aagctt ${ }^{-2000}$ agtggatatcaatacttggg or 5 '-ctcggeggec ${ }^{\text {HindIII }}$ aagett ${ }^{-600}$ catgetcgaaaaaatcaggt and 5 '-tctagtgtct ${ }^{\text {HindIII }}$ aagctt ${ }^{+140}$ gttagctgtaagattgatcaa) and subcloned into HindIII digested pGL4.23 using an InFusion HD Cloning Kit (Takara Bio Inc.). One day before transfection, the cells were seeded into 6-well plates to a density of $2 \times 10^{5}$ per well. Transfections were carried out using Lipofectamine 3000 (Thermo Fisher Scientific) according to the manufacturer's protocol. Transfected cells were harvested after an additional 24 h. Results of one representative experiment are presented as fold induction of relative light units normalized to $\beta$-galactosidase activity relative to that observed with the control vectors [42]. Each experiment was repeated at least three times. Error bars indicate the SD from the average of the triplicate samples in one experiment.

\section{Adenoviral vectors}

Ad-CRISPRi $\triangle \mathrm{Np} 63$ was generated by subcloning the gRNA expression cassettes and the dCas9/KRAB expression cassette from pCRISPRi $\triangle \mathrm{Np} 63 \mathrm{~A} / \mathrm{B}$ amplified using PCR primers (5'- gtaactataacggtc cttttacggttcetggcetttt and 5'attacctctttctcegctccccagcatgectgctattct) and subcloned into linearized pAdenoX vector using Adeno- $X$ Adenoviral System 3 Universal according to manufacturer's protocol (Takara Bio Inc.). The viral titer for each vector was determined using an Adeno- $\mathrm{X}^{\mathrm{TM}}$ Rapid Titer Kit (Takara Bio Inc.), and the optimal multiplicity of infection (MOI) was determined by infecting each cell line with Ad-CMV/ GFP and assessing expression of GFP [50].

\section{Colony formation assay}

Cells were first plated at a density of $2 \times 10^{5}$ cells per well in 6-well plates $24 \mathrm{~h}$ before virus infection. The following day, Ad-empty and Ad-CRISPRi $\triangle$ Np63 were used at a MOI of 600 to infect EBC2 cells, at a MOI of 300 to infect TE8 cells, and at a MOI of 1500 to infect KYSE70 and HaCaT cells. After incubation for $24 \mathrm{~h}$, the cells were harvested by incubation with trypsin/EDTA and counted. EBC2 and KYSE70 cells were then plated in triplicate at a density of $5 \times 10^{2}$ cells per well in 6-well plates, while TE8 and $\mathrm{HaCaT}$ cells were plated in triplicate at a density of $1 \times 10^{3}$ cells per well. After incubation for 14 days, the cells were fixed, stained with Diff-Quik (Sysmex, Kobe, Japan) [51], and colonies (groups of at least 50 aggregated cells) were counted. The mean number of colonies in the control group was arbitrarily set to $100 \%$, and all other counts were normalized to the control, and percent specific cytotoxicity towards colony formation was calculated.

\section{TUNEL staining}

Terminal deoxynucleotidyltransferase-mediated dUTP-biotin nick end labeling (TUNEL) was performed to detect apoptosis using the DeadEnd Colorimetric TUNEL System (Promega, Madison, WI, USA) according to the manufacturer's protocol.

\section{Immunoblot analysis}

Cells were lysed in ice-cold M-PER lysis buffer purchased from Thermo Fisher Scientific. Cell lysates were clarified by centrifugation ( $20 \mathrm{~min}$ at $15,000 \mathrm{rpm}$ and $4^{\circ} \mathrm{C}$ ), 
and protein concentrations were determined using BCA protein assays (Thermo Fisher Scientific). Equal amounts of protein were separated using SDS-PAGE. The resolved proteins were then transferred to Hybond PVDF transfer membranes (Millipore, Bedford, MT, USA) and incubated with primary and secondary antibodies according to the Supersignal ${ }^{\circledR}$ West Pico chemiluminescence protocol (Thermo Fisher Scientific). Primary anti-TAp63 and anti$\triangle \mathrm{Np} 63$ antibodies were obtained from Cell Signaling Technology (Beverly, MA, USA), and an anti-Cas9 antibody was obtained from Novus Biologicals, Inc. (Littleton, CO, USA). An anti- $\beta$-actin antibody was obtained from Santa Cruz Biotechnology (Santa Cruz, CA, USA). Secondary horseradish peroxidase (HRP)-conjugated antibodies were from Jackson Immunoresearch Laboratories (West Grove, PA, USA).

\section{Immunohistochemistry}

Sections were deparaffinized through a series of xylene, graded ethanol, and water immersion steps. After autoclaving the sections in target retrieval solution (Dako, Carpinteria, CA, USA; for $15 \mathrm{~min}$, they were incubated with $3 \%$ hydrogen peroxide for $5 \mathrm{~min}$ to block endogenous peroxidase activity. Specimens were then incubated overnight at $4^{\circ} \mathrm{C}$ with anti- $\Delta \mathrm{Np} 63$ antibody (clone 11F12.1, 1:500 dilution; Millipore, Bedford, MA, USA). After three washes with TBS, the sections were treated with streptavidin-biotin complex (Envision System labeled polymer, HRP, Dako, Carpinteria, CA) for $60 \mathrm{~min}$ at room temperature. Immunoreactions were visualized using 3,3'-diaminobenzidine (DAB) substrate-chromogen solution (Cytomation Liquid DAB Substrate Chromogen System, Dako) and counterstained with hematoxylin. Sections were then immersed in an ethanol and xylene bath and mounted on slides for examination. For immunohistochemical analysis, 40 lung SCC tissue samples, 40 pulmonary adenocarcinoma tissue samples and 40 esophageal SCC samples in tissue sections were obtained from patients who underwent surgical treatment at Kawasaki Hospital, Okayama, Japan. The experimental protocol was approved by the Ethics Review Committee of Kawasaki Medical School (Ethics Committee reference number: 1310).

\section{Mouse experiments}

The experimental protocol was approved by the Ethics Review Committee for Animal Experimentation of Kawasaki University Graduate School of Medicine and Dentistry (Ethics Committee reference number: 15-046). EBC2 lung SCC cells were plated in $15 \mathrm{~cm}$ dishes at a density of $4 \times 10^{6}$ cells per dish, cultured overnight at $37^{\circ} \mathrm{C}$, and then infected with Ad-empty or Ad-CRISPRi $\triangle N p 63$. After incubation for an additional $24 \mathrm{~h}$, the cells were harvested and resuspended in culture medium. Human lung cancer xenografts were established in 6-week-old female $\mathrm{BALB} / \mathrm{c}$ nude mice
(CLEA Japan, Tokyo, Japan) through subcutaneous injection of adenovirus-treated EBC cells $\left(2 \times 10^{6}\right.$ cells $\left./ 100 \mu \mathrm{l}\right)$ into their dorsal flank. The mice were then closely observed, and tumors were measured twice a week. Tumor volumes were calculated using the formula $a \times b^{2} \times 0.5$, where $a$ and $b$ are the large and small diameters, respectively.

\section{Statistical analysis}

Differences between the study groups were evaluated using Student's $t$-test or Fisher's exact test. Values of $p<0.05$ were considered significant.

\section{Author contributions}

M.Y., E.Y., T.S. performed the experiments. T.F. and T.S. designed the study. T.F. and T.S. wrote the manuscript. E.Y., T.S. provided technical help. T. Yamamoto, T. Yamatsuji, T.U., N.T. and Y.N. provided scientific discussion. All authors contributed to the discussion and review of the manuscript.

\section{ACKNOWLEDGMENTS}

This study was supported by the Japan Agency for Medical Research and Development (AMED) to $T$. Sakuma, T. Ushijima and T. Fukazawa and the Ministry of Education, Science, and Culture, Japan to T. Fukazawa, and Y. Naomoto. The authors thank N Hattori (Division of Epigenomics, National Cancer Center Research Institute), M. Minoru, M. Takaoka, M. Iwai, T. Yukawa (Department of General Surgery, Kawasaki Medical School), T. Ikeda, N. Miyake (General Medical Center Research Unit, Kawasaki Medical School) and M. Durbin for technical assistant and discussions.

\section{CONFLICTS OF INTEREST}

The authors have declared that no conflicts of interest exists.

\section{FUNDING}

This study was supported by the Practical Research for Innovative Cancer Control from the Japan Agency for Medical Research and Development (AMED) to T. Sakuma, T. Ushijima and T. Fukazawa under Grant Number JP17ck0106237.

\section{REFERENCES}

1. Liu Q, Segal DJ, Ghiara JB, Barbas CF 3rd. Design of polydactyl zinc-finger proteins for unique addressing within complex genomes. Proc Natl Acad Sci U S A. 1997; 94:5525-30. 
2. Deng D, Yan C, Pan X, Mahfouz M, Wang J, Zhu JK, Shi Y, Yan N. Structural basis for sequence-specific recognition of DNA by TAL effectors. Science. 2012; 335:720-3. https:// doi.org/10.1126/science.1215670.

3. Jinek M, Chylinski K, Fonfara I, Hauer M, Doudna JA, Charpentier E. A programmable dual-RNA-guided DNA endonuclease in adaptive bacterial immunity. Science. 2012; 337:816-21. https://doi.org/10.1126/science.1225829.

4. Cong L, Ran FA, Cox D, Lin S, Barretto R, Habib N, Hsu PD, Wu X, Jiang W, Marraffini LA, Zhang F. Multiplex genome engineering using CRISPR/Cas systems. Science. 2013; 339:819-23. https://doi.org/10.1126/science.1231143.

5. La Russa MF, Qi LS. The New State of the Art: Cas9 for Gene Activation and Repression. Mol Cell Biol. 2015; 35:3800-9. https://doi.org/10.1128/mcb.00512-15.

6. Ferlay J, Soerjomataram I, Dikshit R, Eser S, Mathers C, Rebelo M, Parkin DM, Forman D, Bray F. Cancer incidence and mortality worldwide: sources, methods and major patterns in GLOBOCAN 2012. Int J Cancer. 2015; 136:E359-86. https://doi.org/10.1002/ijc.29210.

7. Tsao AS, Scagliotti GV, Bunn PA Jr, Carbone DP, Warren GW, Bai C, de Koning HJ, Yousaf-Khan AU, McWilliams A, Tsao MS, Adusumilli PS, Rami-Porta $\mathrm{R}$, Asamura $\mathrm{H}$, et al. Scientific Advances in Lung Cancer 2015. J Thorac Oncol. 2016; 11:613-38. https:// doi.org/10.1016/j.jtho.2016.03.012.

8. Pennathur A, Gibson MK, Jobe BA, Luketich JD. Oesophageal carcinoma. Lancet. 2013; 381:400-12. https:// doi.org/10.1016/s0140-6736(12)60643-6.

9. Colquhoun A, Arnold M, Ferlay J, Goodman KJ, Forman D, Soerjomataram I. Global patterns of cardia and non-cardia gastric cancer incidence in 2012. Gut. 2015; 64:1881-8. https://doi.org/10.136/gutjnl-2014-308915.

10. Vilgelm A, El-Rifai W, Zaika A. Therapeutic prospects for $\mathrm{p} 73$ and $\mathrm{p} 63$ : rising from the shadow of p53. Drug Resist Updat. 2008; 11:152-63. https:// doi.org/10.1016/j.drup.2008.08.001.

11. Massion PP, Taflan PM, Jamshedur Rahman SM, Yildiz P, Shyr Y, Edgerton ME, Westfall MD, Roberts JR, Pietenpol JA, Carbone DP, Gonzalez AL. Significance of p63 amplification and overexpression in lung cancer development and prognosis. Cancer Res. 2003; 63:7113-21.

12. Deyoung MP, Ellisen LW. p63 and p73 in human cancer: defining the network. Oncogene. 2007; 26:5169-83. https:// doi.org/10.1038/sj.onc.1210337.

13. Yugawa T, Narisawa-Saito M, Yoshimatsu Y, Haga K, Ohno S, Egawa N, Fujita M, Kiyono T. DeltaNp63alpha repression of the Notch1 gene supports the proliferative capacity of normal human keratinocytes and cervical cancer cells. Cancer Res. 2010; 70:4034-44. https:// doi.org/10.1158/0008-5472.can-09-4063.

14. Lee HO, Lee JH, Choi E, Seol JY, Yun Y, Lee H. A dominant negative form of p63 inhibits apoptosis in a p53-independent manner. Biochem Biophys Res Commun. 2006; 344:166-72. https://doi.org/10.1016/j. bbrc.2006.03.128.

15. Cam M, Gardner HL, Roberts RD, Fenger JM, Guttridge DC, London CA, Cam H. DeltaNp63 mediates cellular survival and metastasis in canine osteosarcoma. Oncotarget. 2016; 7:48533-46. https://doi.org/10.18632/oncotarget. 10406.

16. Hibi K, Trink B, Patturajan M, Westra WH, Caballero OL, Hill DE, Ratovitski EA, Jen J, Sidransky D. AIS is an oncogene amplified in squamous cell carcinoma. Proc Natl Acad Sci U S A. 2000; 97:5462-7.

17. Sakuma T, Nishikawa A, Kume S, Chayama K, Yamamoto T. Multiplex genome engineering in human cells using allin-one CRISPR/Cas9 vector system. Sci Rep. 2014; 4:5400. https://doi.org/10.1038/srep05400.

18. Looman C, Abrink M, Mark C, Hellman L. KRAB zinc finger proteins: an analysis of the molecular mechanisms governing their increase in numbers and complexity during evolution. Mol Biol Evol. 2002; 19:2118-30.

19. Gilbert LA, Larson MH, Morsut L, Liu Z, Brar GA, Torres SE, Stern-Ginossar N, Brandman O, Whitehead EH, Doudna JA, Lim WA, Weissman JS, Qi LS. CRISPR-mediated modular RNA-guided regulation of transcription in eukaryotes. Cell. 2013; 154:442-51. https:// doi.org/10.1016/j.cell.2013.06.044.

20. Klijn C, Durinck S, Stawiski EW, Haverty PM, Jiang Z, Liu H, Degenhardt J, Mayba O, Gnad F, Liu J, Pau G, Reeder J, Cao Y, et al. A comprehensive transcriptional portrait of human cancer cell lines. Nat Biotechnol. 2015; 33:306-12. https://doi.org/10.1038/nbt.3080.

21. Barretina J, Caponigro G, Stransky N, Venkatesan K, Margolin AA, Kim S, Wilson CJ, Lehar J, Kryukov GV, Sonkin D, Reddy A, Liu M, Murray L, et al. The Cancer Cell Line Encyclopedia enables predictive modelling of anticancer drug sensitivity. Nature. 2012; 483:603-7. https://doi.org/10.1038/nature11003.

22. Wilson RC, Doudna JA. Molecular mechanisms of RNA interference. Annu Rev Biophys. 2013; 42:217-39. https:// doi.org/10.1146/annurev-biophys-083012-130404.

23. Carthew RW, Sontheimer EJ. Origins and Mechanisms of miRNAs and siRNAs. Cell. 2009; 136:642-55. https:// doi.org/10.1016/j.cell.2009.01.035.

24. Franceschini A, Meier R, Casanova A, Kreibich S, Daga $\mathrm{N}$, Andritschke D, Dilling S, Ramo P, Emmenlauer M, Kaufmann A, Conde-Alvarez R, Low SH, Pelkmans L, et al. Specific inhibition of diverse pathogens in human cells by synthetic microRNA-like oligonucleotides inferred from RNAi screens. Proc Natl Acad Sci U S A. 2014; 111:4548-53. https://doi.org/10.1073/pnas.1402353111.

25. Gilbert LA, Horlbeck MA, Adamson B, Villalta JE, Chen Y, Whitehead EH, Guimaraes C, Panning B, Ploegh HL, Bassik MC, Qi LS, Kampmann M, Weissman JS. Genome-Scale CRISPR-Mediated Control of Gene 
Repression and Activation. Cell. 2014; 159:647-61. https:// doi.org/10.1016/j.cell.2014.09.029.

26. Hsu PD, Scott DA, Weinstein JA, Ran FA, Konermann S, Agarwala V, Li Y, Fine EJ, Wu X, Shalem O, Cradick TJ, Marraffini LA, Bao G, Zhang F. DNA targeting specificity of RNA-guided Cas9 nucleases. Nat Biotechnol. 2013; 31:827-32. https://doi.org/10.1038/nbt.2647.

27. Jiang W, Bikard D, Cox D, Zhang F, Marraffini LA. RNA-guided editing of bacterial genomes using CRISPRCas systems. Nat Biotechnol. 2013; 31:233-9. https:// doi.org/10.1038/nbt.2508.

28. Fu Y, Sander JD, Reyon D, Cascio VM, Joung JK. Improving CRISPR-Cas nuclease specificity using truncated guide RNAs. Nat Biotechnol. 2014; 32:279-84. https://doi.org/10.1038/nbt.2808.

29. Shen B, Zhang W, Zhang J, Zhou J, Wang J, Chen L, Wang L, Hodgkins A, Iyer V, Huang X, Skarnes WC. Efficient genome modification by CRISPR-Cas 9 nickase with minimal off-target effects. Nat Methods. 2014; 11:399-402. https://doi.org/10.1038/nmeth.2857.

30. Kuscu C, Arslan S, Singh R, Thorpe J, Adli M. Genomewide analysis reveals characteristics of off-target sites bound by the Cas9 endonuclease. Nat Biotechnol. 2014; 32:677-83. https://doi.org/10.1038/nbt.2916.

31. Wu X, Scott DA, Kriz AJ, Chiu AC, Hsu PD, Dadon DB, Cheng AW, Trevino AE, Konermann S, Chen S, Jaenisch R, Zhang F, Sharp PA. Genome-wide binding of the CRISPR endonuclease Cas9 in mammalian cells. Nat Biotechnol. 2014; 32:670-6. https://doi.org/10.1038/nbt.2889.

32. Abbas HA, Bui NHB, Rajapakshe K, Wong J, Gunaratne P, Tsai KY, Coarfa C, Flores ER. Distinct TP63 Isoform-Driven Transcriptional Signatures Predict Tumor Progression and Clinical Outcomes. Cancer Res. 2018; 78:451-462.

33. Si H, Lu H, Yang X, Mattox A, Jang M, Bian Y, Sano E, Viadiu H, Yan B, Yau C, Ng S, Lee SK, Romano RA, et al. TNF-alpha modulates genome-wide redistribution of DeltaNp63alpha/TAp73 and NF-kappaB cREL interactive binding on TP53 and AP-1 motifs to promote an oncogenic gene program in squamous cancer. Oncogene. 2016; 35:5781-94. https://doi.org/10.1038/onc.2016.112.

34. Vasilaki E, Morikawa M, Koinuma D, Mizutani A, Hirano Y, Ehata S, Sundqvist A, Kawasaki N, Cedervall J, Olsson AK, Aburatani H, Moustakas A, Miyazono K, Heldin CH. Ras and TGF-beta signaling enhance cancer progression by promoting the DeltaNp63 transcriptional program. Sci Signal. 2016; 9:ra84. https://doi.org/10.1126/scisignal.aag3232.

35. Melino G, Memmi EM, Pelicci PG, Bernassola F. Maintaining epithelial stemness with p63. Sci Signal. 2015; 8:re9. https://doi.org/10.1126/scisignal.aaa1033.

36. Arason AJ, Jonsdottir HR, Halldorsson S, Benediktsdottir $\mathrm{BE}$, Bergthorsson JT, Ingthorsson $\mathrm{S}$, Baldursson $\mathrm{O}$, Sinha S, Gudjonsson T, Magnusson MK. deltaNp63 has a role in maintaining epithelial integrity in airway epithelium. PLoS One. 2014; 9:e88683. https:// doi.org/10.1371/journal.pone.0088683. eCollection 2014.

37. Tata PR, Mou H, Pardo-Saganta A, Zhao R, Prabhu M, Law BM, Vinarsky V, Cho JL, Breton S, Sahay A, Medoff BD, Rajagopal J. Dedifferentiation of committed epithelial cells into stem cells in vivo. Nature. 2013; 503:218-23. https:// doi.org/10.1038/nature12777.

38. Biasco L, Baricordi C, Aiuti A. Retroviral integrations in gene therapy trials. Mol Ther. 2012; 20:709-16. https:// doi.org/10.1038/mt.2011.289.

39. Cesana D, Ranzani M, Volpin M, Bartholomae C, Duros C, Artus A, Merella S, Benedicenti F, Sergi Sergi L, Sanvito F, Brombin C, Nonis A, Serio CD, et al. Uncovering and dissecting the genotoxicity of self-inactivating lentiviral vectors in vivo. Mol Ther. 2014; 22:774-85. https:// doi.org/10.1038/mt.2014.3.

40. Wu Z, Yang H, Colosi P. Effect of genome size on AAV vector packaging. Mol Ther. 2010; 18:80-6. https:// doi.org/10.1038/mt.2009.255.

41. Kreppel F. Production of high-capacity adenovirus vectors. Methods Mol Biol. 2014; 1089:211-29. https:// doi.org/10.1007/978-1-62703-679-5_15.

42. Fukazawa T, Maeda Y, Sladek FM, Owen-Schaub LB. Development of a cancer-targeted tissue-specific promoter system. Cancer Res. 2004; 64:363-9.

43. Gahery-Segard H, Farace F, Godfrin D, Gaston J, Lengagne R, Tursz T, Boulanger P, Guillet JG. Immune response to recombinant capsid proteins of adenovirus in humans: antifiber and anti-penton base antibodies have a synergistic effect on neutralizing activity. J Virol. 1998; 72:2388-97.

44. Somia N, Verma IM. Gene therapy: trials and tribulations. Nat Rev Genet. 2000; 1:91-9. https://doi.org/10.1038/35038533.

45. Schiedner G, Morral N, Parks RJ, Wu Y, Koopmans SC, Langston C, Graham FL, Beaudet AL, Kochanek S. Genomic DNA transfer with a high-capacity adenovirus vector results in improved in vivo gene expression and decreased toxicity. Nat Genet. 1998; 18:180-3. https://doi. org/10.1038/ng0298-180.

46. Ehrke-Schulz E, Zhang W, Schiwon M, Bergmann T, Solanki M, Liu J, Boehme P, Leitner T, Ehrhardt A. Cloning and Large-Scale Production of High-Capacity Adenoviral Vectors Based on the Human Adenovirus Type 5. J Vis Exp. 2016; e52894:e52894. https://doi.org/10.3791/52894.

47. Fukazawa T, Maeda Y, Durbin ML, Nakai T, Matsuoka J, Tanaka H, Naomoto Y, Tanaka N. Pulmonary adenocarcinoma-targeted gene therapy by a cancer- and tissue-specific promoter system. Mol Cancer Ther. 2007; 6:244-52. https://doi.org/10.1158/1535-7163.mct-06-0408.

48. Ulasov I, Borovjagin AV, Kaverina N, Schroeder B, Shah N, Lin B, Baryshnikov A, Cobbs C. MT1-MMP silencing by an shRNA-armed glioma-targeted conditionally replicative adenovirus (CRAd) improves its anti-glioma efficacy in vitro and in vivo. Cancer Lett. 2015; 365:240-50. https:// doi.org/10.1016/j.canlet.2015.06.002. 
49. Nakagawa Y, Sakuma T, Sakamoto T, Ohmuraya M, Nakagata N, Yamamoto T. Production of knockout mice by DNA microinjection of various CRISPR/Cas9 vectors into freeze-thawed fertilized oocytes. BMC Biotechnol. 2015; 15:33. https://doi.org/10.1186/s12896-015-0144-x.

50. Gu J, Zhang L, Huang X, Lin T, Yin M, Xu K, Ji L, Roth JA, Fang B. A novel single tetracycline-regulative adenoviral vector for tumor-specific Bax gene expression and cell killing in vitro and in vivo. Oncogene. 2002; 21:4757-64. https://doi.org/10.1038/sj.onc.1205582.

51. Menges CW, Sementino E, Talarchek J, Xu J, Chernoff J, Peterson JR, Testa JR. Group I p21-activated kinases (PAKs) promote tumor cell proliferation and survival through the AKT1 and Raf-MAPK pathways. Mol Cancer Res. 2012; 10:1178-88. https://doi.org/10.1158/1541-7786.mcr-12-0082. 